K и переносимость крема Кераворт (имихимод)
в терапии аногенитальных бородавок

М.Р. Рахматулина', А.А. Кубанов ${ }^{1}$, А.В. Самцов², А.В. Сухарев², О.И. Бондарь², А.В. Семененко을

1 ФГБУ «Государственный научный центр дерматовенерологии и косметологии» Минздрава России 107076, Москва, ул. Короленко, д. 3, стр. 6

2 ФГБВОУ ВПО «Военно-медицинская академия им. С.М. Кирова» МО РФ

194044, Санкт-Петербург, ул. Академика Лебедева, 6

${ }^{3}$ ГБОУ ДПО «Российская медицинская академия последипломного образования» Минздрава России 123995, Москва, ул. Баррикадная, д. 2/1

Цель исследования. Оценить эффрективность и безопасность препарата Кераворт (имихимод, крем для наружного применения 5\%) в сравнении с плацебо в терапии аногенитальных бородавок.

Материал и методы. В простое слепое сравнительное плацебо-контролируемое исследование было включено 90 пациентов (44 женщины и 46 мужчин) с диагнозом «аногенитальные бородавки». Пациенты были рандомизированы в две группы: основную ( $n=45)$, получавшую терапию препаратом Кераворт (имихимод, крем 5\%), и группу сравнения ( $n=45)$, получавшую плацебо. Диагноз подтверждался идентификацией вирусов папилломы человека методом полимеразной цепной реакции. Лечение проводилось 3 раза в неделю до исчезновения клинических проявлений заболевания, но не более 16 нед.

Результаты. У 95,6\% пациентов основной группы и у 8,9\% пациентов группы сравнения зарегистрировано полное исчезновение аногенитальных бородавок либо уменьшение количества/площади патологических высыпаний не менее чем на 70\% по сравнению с исходными данными.

В процессе терапии и во время периода наблюдения (28 дней после завершения терапии) у пациентов основной группы не было зарегистрировано рецидивов заболевания. У $11,1 \%$ пациентов группы сравнения выявлено увеличение размеров и/или площади аногенитальных бородавок и/или появление новых высыпаний на коже и слизистых оболочках половых органов. Серьезных нежелательных явлений за время проведения исследования не выявлено.

Заключение. При применении препарата Кераворт (имихимод, крем для наружного применения 5\%) в терапии аногенитальных бородавок установлена достоверно более высокая эфффективность ( $p<0,0000001)$ и сопоставимая безопасность по сравнению с плацебо.

Ключевые слова: аногенитальные бородавки, вирус папилломы человека, имихимод, Кераворт. 


\title{
Clinical efficacy, safety and tolerance of the Kerawort (imiquimod) cream used for treatment of anogenital warts
}

\author{
M.R. Rakhmatulina', A.A. Kubanov', A.V. Samtsov², A.V. Sukharev², O.I. Bondar², A.V. Semenenko³
}

${ }^{1}$ State Research Center of Dermatovenereology and Cosmetology, Ministry of Healthcare of the Russian Federation Korolenko str., 3, bldg 6, Moscow, 107076, Russia

${ }^{2}$ Military Medical Academy named after S.M. Kirov Ministry of Defense of the Russian Federation Akademika Lebedeva str., 2, St. Petersburg, 194044, Russia

${ }^{3}$ Russian Medical Academy of Postgraduate Studies, Ministry of Health of the Russian Federation Barrikadnaya str., 2/1, Moscow, 123995, Russia

\begin{abstract}
Goal of the study. To assess the efficacy and safety of Kerawort (Imiquimod, 5\% cream for topical administration) vs. placebo used for treatment of anogenital warts.

Methods and materials. The single-blind comparative placebo-controlled study involved 90 patients (44 female and 46 male) with anogenital warts. The patients were randomized into two groups: the main group $(n=45)$ receiving treatment with Kerawort (Imiquimod, 5\% cream) and the control group $(n=45)$ receiving placebo. The diagnosis was confirmed by the identification of human papillomavirus by the polymerase chain reaction method. The patients received treatment three times a week until clinical signs disappeared but for not more than 16 weeks.

Results. In $95.6 \%$ of patients from the main group and $8.9 \%$ of patients from the control group, anogenital warts disappeared completely or the quantity/area of pathological eruptions reduced at least by $70 \%$ as compared to the baseline.

No relapses occurred during the treatment and follow-up period (28 days after the completion of treatment) in patients from the main group. An increase in the size and/or area of anogenital warts and/or development of new eruptions on the skin and mucous membrane of the genitals were recorded in $11.1 \%$ of patients from the control group. No serious adverse events were revealed during the study.

Conclusion. Higher efficacy $(p<0.0000001)$ and comparable safety of Kerawort (Imiquimod, 5\% cream for topical administration) used for treatment of anogenital warts vs. placebo were reliably established.
\end{abstract}

Key words: anogenital warts, human papillomavirus, Imiquimod, Kerawort.

Corresponding author: rahmatulina@cnikvi.ru. Vestnik Dermatologii i Venerologii 2015; 1: 129_134.

Папилломавирусная инфекция является одной из наиболее распространенных инфекций, передаваемых половым путем. Инфицирование возбудителем заболевания - вирусом папилломы человека (ВПЧ) может как протекать в латентной фрорме, так и приводить к развитию манифестных проявлений, в том числе злокачественных новообразований аногенитальной локализации.

Наиболее специфичными манифестными проявлениями папилломавирусной инфекции являются аногенитальные (венерические) бородавки. Согласно результатам эпидемиологических исследований, заболеваемость аногенитальными бородавками в Северной Америке составляет 100 на 100000 населения, а в Европе ежегодно регистрируется более 500000 новых случаев заболеваний, ассоциированных с ВПЧ, в том числе цервикальных неоплазий и рака шейки матки. Показатели заболеваемости манифестными формами папилломавирусной инфекции в Российской Федерации составляют 28,9 на 100000 населения, что существенно отличается от истинной распространенности ВПЧ в популяции [1-3].

Клиническое течение папилломавирусной инфекции во многом зависит от иммунного статуса макроорганизма. Современными исследованиями доказано, что лица с заболеваниями, сопровождающимися иммунодефицитом, имеют бо́льший риск инфицирования ВПЧ, при этом манифестные проявления инфекционного процесса у них нередко характеризуются резистентностью к проводимой терапии [1].

Наиболее частой локализацией аногенитальных бородавок у мужчин является препуциальный мешок (головка полового члена, венечная борозда, уздечка, внутренний листок крайней плоти) и тело полового члена; также инфекционный процесс может поражать 
кожу мошонки, промежности, паховой и анальной областей. У женщин клинические проявления папилломавирусной инфекции чаще локализуются в области половых губ, на слизистой оболочке наружного отверстия уретры, промежности, анальной области, девственной плеве, слизистой оболочке влагалища и экзоцервикса. Внутрианальные бородавки, как правило, наблюдаются у лиц, практикующих анальные половые контакты.

Заболевание может протекать субъективно бессимптомно, но в ряде случаев сопровождается зудом, жжением, болезненностью и кровотечением в области высыпаний. Аногенитальные бородавки могут травмироваться в результате трения, вызванного механическими действиями либо одеждой, что нередко приводит к вторичному инфицированию, а также возрастанию риска заражения сексуального партнера [2, 4, 5].

В настоящее время терапия аногенитальных бородавок направлена на деструкцию патологических высыпаний и включает:

- цитотоксические методы;

химические методы;

иммуномодуляторы для местного применения;

- физические методы;

хирургическое иссечение.

Эффрективность различных методов лечения аногенитальных бородавок сопоставима и с учетом проведения повторных курсов лечения составляет $60-80 \%$, при этом риск развития рецидивов варьирует от 20 до $30 \%[6,7]$.

Механизм действия цитотоксических препаратов (подофиллина, подофиллотоксина) заключается в разрушении клеток эпителия за счет антипролиферативного воздействия или химической деструкции. При этом лекарственные средства не отличаются избирательной направленностью в отношении клеток, инфицированных ВПЧ, и их применение сопровождается частыми побочными эффектами и высоким риском развития рецидивов.

К фризическим методам лечения аногенитальных бородавок относят электрокоагуляцию, лазерную деструкцию, радиохирургическую деструкцию, криодеструкцию, которые демонстрируют высокую клиническую эффрективность. Однако их применение также не исключает возникновения рецидивов, так как длительная персистенция ВПЧ возможна и во внешне здоровой коже [6].

Лечение аногенитальных бородавок путем наружного применения препаратов интерферона (ИФН), как показывают результаты современных исследований, недостаточно эфрфективно. Кроме того, процедура внутриочагового введения ИФН является болезненной и дорогостоящей $[4,7]$.

Таким образом, современные средства терапии клинических проявлений папилломавирусной инфекции по своей сути являются симптоматическими, не позволяют добиться эрадикации ВПЧ и не предупреждают дальнейшей передачи вируса.
Выявленные достоверные изменения интерфероногенеза и локального иммунитета при папилломавирусной инфекции послужили основанием для разработки новых методов терапии аногенитальных бородавок с применением препаратов, обладающих способностью к деструкции патологических очагов и возможностью коррекции локального иммунитета.

Модификатор иммунного ответа - препарат Кераворт (имихимод) применяется в терапии аногенитальных бородавок и характеризуется способностью $\mathrm{k}$ стимуляции моноцитов, макрофагов и кератиноцитов через индукцию ИФН- $\alpha$, фактора некроза опухолей и интерлейкинов. При местном применении препарата наблюдается угнетение процессов ангиогенеза за счет усиления продукции интерлейкина-18 и ИФН- $\gamma$. Характерной особенностью препарата является снижение частоты рецидивов заболевания благодаря опосредованной элиминации ВПЧ. Применение Кераворта повышает уровень комфорта и комплаентности пациента, а также дополнительно стимулирует пациента к лечению.

Цель исследования: оценить эффективность и безопасность препарата Кераворт (имихимод, крем для наружного применения 5\%) в сравнении с плацебо в терапии аногенитальных бородавок.

\section{Материал и методы}

Данное исследование являлось простым слепым сравнительным рандомизированным плацебоконтролируемым. В исследовании приняли участие 90 пациентов (44 женщины и 46 мужчин) с диагнозом «аногенитальные бородавки», которые после успешного окончания процедур скрининга были рандомизированы на две группы: основную (45 пациентов), получавшую терапию препаратом Кераворт (имихимод, крем для наружного применения 5\%), и группу сравнения (45 пациентов), получавшую терапию плацебо в форме крема для наружного применения. Средний возраст пациентов составил 30,2 года.

У всех пациентов на момент скрининга были исключены сопутствующие заболевания, в том числе инфекции, передаваемые половым путем: сифилис, ВИЧ-инфекция, гонококковая и трихомонадная инфекции, генитальный герпес с манифестными проявлениями. При проведении исследования цервикального соскоба по Папаниколау у 26 женщин был установлен I тип (класс) цитологического мазка, у 18 женщин II тип (класс) цитологического мазка.

Оценка эффективности лечения проводилась на визитах 3 (день $21 \pm 2$ ), 4 (день $35 \pm 2$ ), 5 (день $63 \pm 2$ ), 6 (день $91 \pm 7$ ), 7 (день $119 \pm 2$ ) и 8 (день $147 \pm 2$ ) по следующим параметрам:

- наличие/отсутствие субъективных симптомов (по 4-уровневой шкале: 0 - отсутствие, 1 - слабая, 2 - умеренная, 3 - сильная) и объективных симптомов заболевания (количество патологических элементов на коже или их площадь); 
- частота рецидивирования аногенитальных (венерических) бородавок.

Итоговая оценка эффрективности терапии проводилась по следующим критериям:

клиническое выздоровление (отсутствие клинических симптомов заболевания);

- значительное улучшение (уменьшение количества/ площади патологических высыпаний не менее чем на 70\% по сравнению с исходными данными);

шлучшение (уменьшение количества/площади патологических высыпаний менее чем на $70 \%$ по сравнению с исходными данными);

без изменений (отсутствие динамики количества/ площади патологических высыпаний по сравнению с исходными данными);

- ухудшение (увеличение количества/площади патологических высыпаний по сравнению с исходными данными и/или появление новых высыпаний).

Пациентам основной группы была назначена терапия препаратом Кераворт, крем для наружного применения 5\% по схеме: 3 раза в неделю перед сном. Препарат наносился тонким слоем на предварительно очищенную поверхность пораженных участков кожи, аккуратно втирался до полного впитывания и оставлялся на коже в течение 6-10 ч. Пациенты группы сравнения наносили на область аногенитальных бородавок плацебо-крем по аналогичной схеме. Лечение продолжалось до исчезновения видимых клинических проявлений заболевания, но не более 16 нед.

Безопасность применения препарата оценивалась по результатам регистрации нежелательных лекарственных явлений и данным лабораторных исследований (клинические анализы крови и мочи, биохимический анализ крови).

\section{Результаты и их обсуждение}

В ходе исследования оценивалась динамика субъективных и объективных проявлений заболевания у больных исследуемых групп (табл. 1-3).

В основной группе исследование завершили 42 (93,3\%) пациента, в группе сравнения - 27 (60,0\%) пациентов $(p=0,0003)$. Как в основной группе, так и в группе сравнения 2 (4,4\%) и 2 (4,4\%) пациента соответственно отказались от дальнейшего участия в исследовании по причине неэффрективности терапии. При этом следует отметить, что пациенты основной группы, выбывшие из исследования, получали препарат Кераворт в течение только 28 дней при рекомендуемом курсе лечения 16 нед., что свидетельствует скорее не о низкой эфффективности препарата, а об отсутствии комплаентности пациентов.

У одного пациента $(2,2 \%)$ основной группы было зарегистрировано нежелательное явление легкой степени тяжести, у пациентов группы сравнения нежелательные лекарственные явления не обнаруживались. Эфрфективность терапии у пациента с нежелательным явлением на последнем (пятом) визите была оценена врачом-исследователем как «значительное улучшение».

В период наблюдения и после завершения применения препарата (28 дней) у пациентов, получавших лечение препаратом Кераворт, крем для наружного применения 5\%, рецидивы заболевания не регистрировались. В группе сравнения у $5(11,1 \%)$ больных было отмечено увеличение размеров и/или площади патологических высыпаний, а также появление новых аногенитальных бородавок на коже и слизистых оболочках.

Согласно полученным данным, у 43 (95,6\%) пациентов, получавших лечение препаратом Кераворт, было достигнуто полное исчезновение аногенитальных бородавок («клиническое выздоровление») либо разрешение кожных высыпаний не менее чем на $70 \%$ по сравнению с исходными данными («значительное улучшение»). Аналогичный показатель в группе сравнения составил 8,9\% (4 пациента). Различия в эффрективности терапии между группами были статистически достоверными ( $p<0,0000001)$ (рисунок). Результаты клинического исследования доказывают высокую эффрективность препарата Кераворт (имихимод, крем для наружного применения) у пациентов с аногенитальными (венерическими) бородавками.

При оценке показателей общеклинических анализов крови, мочи и биохимических показателей крови изменений после проведенного лечения выявлено не было как в группе пациентов, использовавших в каче-

Таблица 1 Динамика патологических элементов на коже по визитам (B) в ходе исследования

\begin{tabular}{|c|c|c|c|c|c|c|c|c|c|c|c|c|c|c|}
\hline \multirow{2}{*}{$\begin{array}{l}\text { Патологические } \\
\text { элементы на коже }\end{array}$} & \multicolumn{7}{|c|}{ Плацебо (по визитам) } & \multicolumn{7}{|c|}{ Имихимод (по визитам) } \\
\hline & B 1 & B 3 & B 4 & B 5 & B 6 & B 7 & B 8 & B 1 & B 3 & B 4 & B 5 & B 6 & B 7 & B 8 \\
\hline 0 = отсутствие & 8 & 8 & 10 & 11 & 7 & 6 & 9 & 5 & 8 & 15 & 21 & 19 & 17 & 22 \\
\hline 1 = слабая & 4 & 5 & 2 & 2 & 1 & 1 & 1 & 9 & 12 & 16 & 11 & 7 & 3 & 2 \\
\hline 2 = умеренная & 28 & 27 & 27 & 22 & 20 & 19 & 21 & 27 & 22 & 11 & 4 & 2 & 2 & 0 \\
\hline 3 = сильная & 5 & 5 & 6 & 7 & 3 & 3 & 2 & 4 & 3 & 1 & 1 & 0 & 0 & 0 \\
\hline Всего & 45 & 45 & 45 & 42 & 31 & 29 & 33 & 45 & 45 & 45 & 43 & 28 & 22 & 24 \\
\hline
\end{tabular}


Таблица 2 Динамика зуда/жжения по визитам (B) в ходе исследования

\begin{tabular}{lcccccccccccccc}
\hline \multirow{2}{*}{$\begin{array}{l}\text { Зуд/Жжение } \\
\text { кожных покровов }\end{array}$} & В 1 & В 3 & В 4 & В 5 & В 6 & В 7 & В 8 & В 1 & В 3 & В 4 & В 5 & В 6 & В 7 & В 8 \\
\hline 0 = отсутствие & 33 & 32 & 30 & 33 & 27 & 24 & 29 & 34 & 35 & 36 & 34 & 27 & 22 & 24 \\
\hline 1 = слабая & 7 & 11 & 13 & 7 & 4 & 3 & 2 & 5 & 10 & 7 & 3 & 1 & 0 & 0 \\
\hline 2 = умеренная & 4 & 1 & 1 & 1 & 0 & 2 & 2 & 6 & 0 & 0 & 0 & 0 & 0 & 0 \\
\hline 3 = сильная & 1 & 1 & 1 & 1 & 0 & 0 & 0 & 0 & 0 & 0 & 0 & 0 & 0 & 0 \\
\hline Всего & 45 & 45 & 45 & 42 & 31 & 29 & 33 & 45 & 45 & 45 & 43 & 28 & 22 & 24 \\
\hline
\end{tabular}

Таблица 3 Динамика болезненности кожи по визитам (B) в ходе исследования

\begin{tabular}{|c|c|c|c|c|c|c|c|c|c|c|c|c|c|c|}
\hline \multirow{2}{*}{ Болезненность кожи } & \multicolumn{7}{|c|}{ Плацебо (по визитам) } & \multicolumn{7}{|c|}{ Имихимод (по визитам) } \\
\hline & B 1 & B 3 & B 4 & B 5 & B 6 & B 7 & B 8 & B 1 & B 3 & B 4 & B 5 & B 6 & B 7 & B 8 \\
\hline 0 = отсутствие & 35 & 37 & 36 & 36 & 29 & 26 & 31 & 41 & 43 & 42 & 37 & 28 & 21 & 23 \\
\hline 1 = слабая & 7 & 6 & 7 & 5 & 2 & 3 & 2 & 1 & 2 & 1 & 0 & 0 & 1 & 1 \\
\hline 2 = умеренная & 1 & 1 & 1 & 0 & 0 & 0 & 0 & 3 & 0 & 0 & 0 & 0 & 0 & 0 \\
\hline 3 = сильная & 2 & 1 & 1 & 1 & 0 & 0 & 0 & 0 & 0 & 0 & 0 & 0 & 0 & 0 \\
\hline Всего & 45 & 45 & 45 & 42 & 31 & 29 & 33 & 45 & 45 & 45 & 43 & 28 & 22 & 24 \\
\hline
\end{tabular}

Плацебо

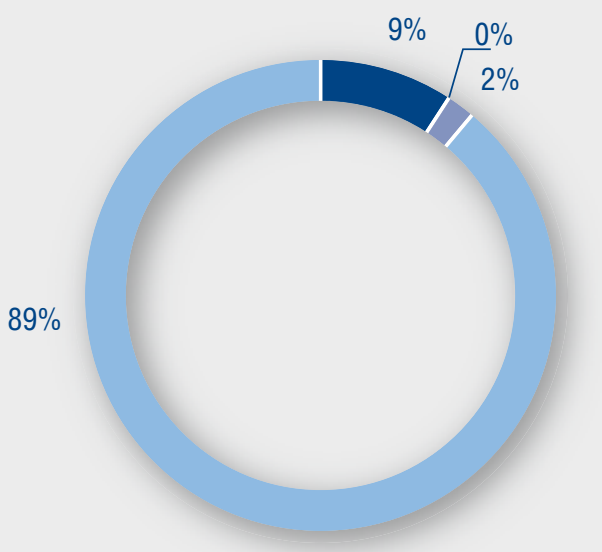

Кераворт

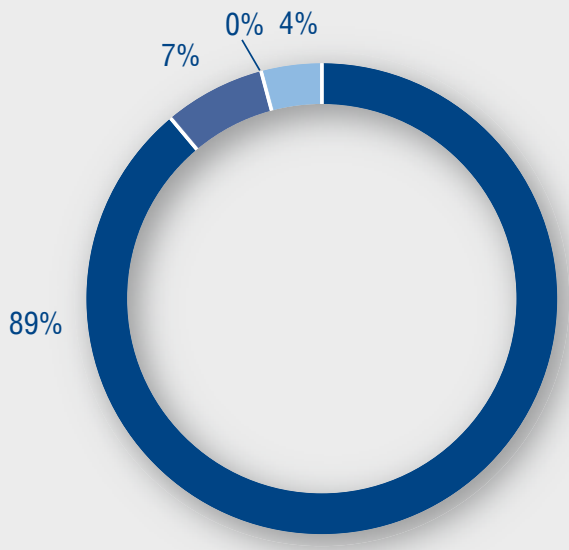

Клиническое выздоровление

Значительное улучшение

Улучшение

Без изменений/Ухудшение

Рисунок. Сравнение эффективности терапии аногенитальных бородавок препаратом Кераворт и плацебо 
стве лечения крем-плацебо, так и в группе пациентов, применявших Кераворт (имихимод, крем для наружного применения 5\%).

Таким образом, при оценке эффективности терапии препаратом Кераворт (имихимод, крем для наружного применения 5\%) у пациентов с аногениальными бородавками в сравнении с эфффективностью плацебо установлено:

снижение интенсивности зуда и жжения в области высыпаний (по оценке пациентами) у $100 \%$ больных, получавших терапию препаратом Кераворт, и у 78\% больных, получавших плацебо;

снижение количества патологических высыпаний на половых органах в процессе терапии (по оценке пациентами) у $11 \%$ больных, получавших терапию препаратом Кераворт, и у $2 \%$ больных, получавших плацебо;

полный регресс высыпаний у 89\% больных, получавших терапию препаратом Кераворт, и у $9 \%$ больных, получавших плацебо; снижение средних значений площади аногенитальных бородавок у $100 \%$ больных, получавших терапию препаратом Кераворт, и у 33\% больных, получавших плацебо;

- отсутствие возникновения рецидивов аногенитальных бородавок у $100 \%$ больных, получавших терапию препаратом Кераворт, и у 88,9\% больных, получавших плацебо;

- отсутствие нежелательных явлений и клинически значимых изменений общеклинических анализов крови, мочи и биохимических показателей крови у 97,2\% больных, получавших терапию препаратом Кераворт, и у 100\% больных, получавших плацебо.

\section{Заключение}

При применении препарата Кераворт (имихимод, крем для наружного применения 5\%) в терапии аногенитальных бородавок установлена достоверно более высокая эфффективность $(p<0,0000001)$ и сопоставимая безопасность по сравнению с плацебо.
1. Gormley R., Kovarik C. Human papillomavirus-related genital disease in the immunocompromised host J Am Acad Dermatol, 2012, Vol 6. — P. 867—880.

2. Kacambas A.D., Lotti T.M. Evropejskoe rukovodstvo po lecheniju dermatologicheskih boleznej: MEDpress-inform 2009; 8-9. [Кацамбас А.Д., Лотти Т.М. Европейское руководство по лечению дерматологических болезней: МЕДпрессинсрорм 2009; 8-9.]

3. Rakhmatulina M.R. New potential of the complex therapy of anogenital papilloma viral infection.Vestn Dermatol Venerol 2011; 2: 79_84. [Рахматулина M.P. Новые возможности комплексной терапии аногенитальной папилломавирусной инсекции. Вестн дерматол венерол 2011; 2: 79—84.]

\section{Литература}

4. Molochkov V.A., Kiselev V.I., Rudyh I.V. i dr. Papillomavirusnaja infekcija. M: Mirada Viva 2008. [Молочков В.А., Киселев В.И., Рудых И.В. и др. Папилломавирусная инсекция. М: Мирада Вива 2008.]

5. Dubenskij V.V. Kliniko-jepidemiologicheskie osobennosti papillomavi-rusnoj infekcii i metody lechenija. Ros zhurn kozh ven bol 2001; 1: 51-56. [Дубенский В.В. Клинико-эпидемиологические особенности папилломавирусной инсрекции и методы лечения. Рос журн кож вен бол 2001; (1): 51—56.]
6. Prilepskaja V.N., Kostava M.N. Vozmozhnosti terapii papillomavirusnoj infekcii. RMZh 2009; 17 (1): 16-19. [Прилепская В.Н., Костава М.Н. Возможности терапии папилломавирусной инфекции. РМЖ 2009; 17 (1): 16-19.]

7. Rogovskaja S.I. Papillomavirusnaja infekcija u zhenshhin i patologija shejki matki. M: GJeOTARMedia 2008. [Роговская С.И. Папилломавирусная инфекция у женщин и патология шейки матки. М: ГЭОТАР-Медиа 2008.]

об авторах:

М.Р. Рахматулина - д.м.н., зам. директора по научно-клинической работе ФГБУ «ГНЦДК» Минздрава России, Москва А.А. Кубанов - д.м.н., профессор, зам. директора по научной работе ФГБУ «ГНЦДК» Минздрава России, Москва А.В. Самцов - д.м.н., профессор, зав. кафедрой кожных и венерических болезней ФГБВОУ ВПО «Военно-медицинская академия им. С.М. Кирова» МО РФ, Санкт-Петербург

А.В. Сухарев - д.м.н., профрессор, зам. начальника кафедры кожных и венерических болезней ФГБВОУ ВПО «Военно-медицинская академия им. С.М. Кирова» МО РФ, Санкт-Петербург

О.И. Бондарь - к.м.Н., зав. отделением кафедры кожных и венерических болезней ФГБВОУ ВПО «Военно-медицинская академия им. С.М. Кирова» МО РФ, Санкт-Петербург

А.В. Семененко - аспирант кафедры дерматовенерологии, микологии и косметологии ГБоУ дПо «Российская академия последипломного образования» Минздрава России, Москва

\section{Конфликт интересов}

Авторы заявляют об отсутствии потенциального конфликта интересов, требующего раскрытия в данной статье 